\title{
Multi Criteria Optimization Approach for Dressing of Vitrified Grinding Wheel
}

\author{
M. A. K. CHOWDHURY, Ateekh Ur REHMAN, M. S. UDDIN, Mohammed ALKAHTANI, Saqib ANWAR
}

\begin{abstract}
Rotary diamond dressers are widely used for the dressing to improve the efficiency of vitrified grinding wheel. The paper focuses on the process parameters, i.e., feed speed of dresser, depth of cut, grinding wheel velocity, velocity ratio between grinding wheel and rotary dresser, number of pass and dressing method (up-cut or downcut) in rotary diamond dressing. The objective is to investigate the effect of these process parameters with their interactions for two response parameters, dressing ratio and overlapped dressed area. As far as the response parameters are concerned, the goal is to maximize dressing ratio and minimize overlapped dressed area simultaneously. Thirty-six experiments were designed and performed. Analysis of variance and multi-criteria optimization approach are opted to find out significant process parameters and optimal parameter setting. Finally, the significant process parameters, dressing method and number of pass are identified as well and the optimal parameter setting is also determined.
\end{abstract}

Keywords: grey relational grade; multi-criteria decision approach; rotary diamond dressing; signal to noise ratio

\section{INTRODUCTION}

In the manufacturing industry, grinding is the most commonly used material removal process to achieve superior finish and geometric integrity on machined work piece [1]. A grinding wheel is a cutting tool, which has abrasive grains distributed throughout the wheel [2]. The material removal efficiency of a grinding wheel decreases with the underlying grinding operations, e.g., cutting forces due to complex interactions between fixed hard abrasive grits and work piece surface, thus affecting the grinding performance. To restore the removal efficiency of the grinding wheel, dressing is required [3]. The restoration of removal efficiency is performed by sharpening and protruding the abrasive cutting edges on the working surface of the grinding wheel. Mechanical dressing is one of the useful options [4]. The rotary diamond dresser is commonly used as mechanical dresser for dressing grinding wheels, particularly, for vitrified grinding wheel [5]. The grinding wheel surface topography generated from dressing affects the performance of subsequent grinding operation [6, 7]. Therefore, dressing conditions, i.e., parameter setting of dressing has significant effect on the dressing performance and on the grinding performance as well.
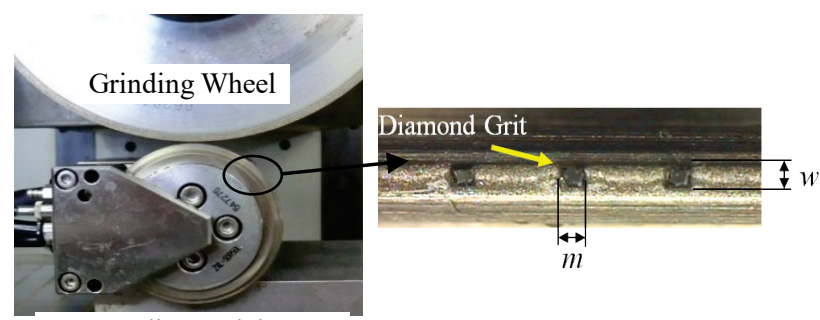

Rotary diamond dresser

Figure 1 Rotary diamond dressing and geometry of rotary diamond dresser

A rotary diamond dresser has diamond grits embedded on the working surface of the dresser, as shown in Fig. 1. In this study, a rotary diamond dresser is selected, where equally sized diamond grits in a given orientation are embedded onto the working surface. These diamond grits are embedded at regular distance with a constant protrusion height and the cross sectional area of the diamond grits forms a square of side $m=w$ (see Fig. 1). In rotary diamond dressing, both dresser and grinding wheel rotate in the same (up-cut) or opposite direction (downcut).

While performing dressing, an overlap between the dresser and the grinding wheel is created which is called depth of cut. At the same time, a relative motion, i.e., feed of dresser, is also maintained between the dresser and the grinding wheel. If the whole area of the grinding wheel is not possible to be dressed by a single pass of dresser, multiple passes are applied. The design parameters of rotary diamond dressing are grinding wheel diameter, rotary diamond dresser diameter, number and size of diamond grit on the circumferential surface of rotary diamond dresser, and the process parameters of rotary diamond dressing are feed speed of dresser, depth of cut, velocity ratio between grinding wheel and rotary diamond dresser, number of pass (single or multiple) and dressing method (up-cut and down-cut). There are two important response parameters resulting from the interaction of the above design and process parameters in the dressing operation, which dictate the end performance of the dressing. They are dressing ratio (percent of circumferential area of grinding wheel that has been dressed) [5, 8-11] and overlapped dressed area (percent of circumferential areas of grinding wheel that are dressed more than once) [8] (refer to Fig. 2).

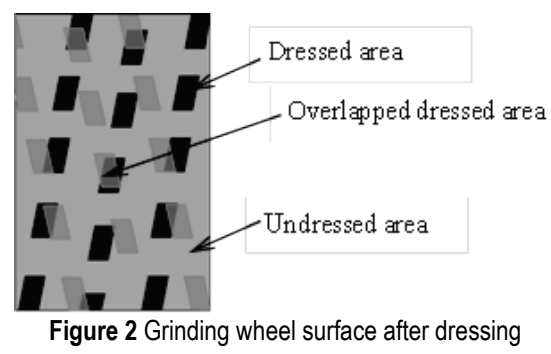

The main aim of dressing is to sharpen the abrasive gains of the whole circumferential surface of grinding wheel [12]. To realize the above mentioned objective, the dresser needs to hit all areas of the circumferential surface of the grinding wheel (high dressing ratio) without hitting the same location repeatedly (low overlapped dressed area) $[5,13]$. Therefore, in dressing operation, dressing ratio and overlapped dressed area are two critical response 
parameters for measuring dressing performance directly. It can also be stated that the two response parameters of dressing have conflicting goals. Thus, often it is quite difficult to obtain the optimum performance of the dressing operation and hence, an optimization approach is needed to tackle this problem, identifying the best set of parameters for dressing. In this paper, we did not consider the surface profile of grinding wheel in the depth wise direction and wear of rotary dresser.

In the past, many authors have studied the effect of different dressing parameters on dressing performance and generation of improved grinding wheel surface topography. Xie et al. [14] conducted electro contact discharge dressing experiments to identify the effect of grit protrusion on grinding performance. Klocke and Linke [15] developed a FE (finite element) model for grinding wheel and showed how the wheel wear is affected by different dressing parameters. Bzymek [16] developed a virtual dressing and truing operation model considering vibration of dressing apparatus. In this model, a user is allowed to define the diamond profile of the grit and the virtual model generates the windowed profile of the grinding wheel surface and surface roughness value. Chowdhury et al. [13] developed the analytical model for rotary diamond dressing correlating the parameters of dressing operation, rotary diamond dresser, and grinding wheel. Later on, Chowdhury et al. [5] developed a simulation system to visualize the grinding wheel topography after rotary diamond dressing. Until now, to the best knowledge of the authors, no study focuses on multicriteria optimization for obtaining optimal parameter setting for dressing.

Optimization of multiple response parameters is a complex scenario as compared to single response parameter [17]. For single response parameter, Taguchi method can provide optimal parameter settings effectively. However, in case of multiple response parameters with contradictory objectives, Taguchi method is not often an effective solution. Grey based Taguchi is getting attention by many researchers as a tool to analyse the processes that have multiple response parameters [18]. Huang and Liao [19] optimized the machining parameters for wire electrical discharge machining using the grey based Taguchi relational analysis. Wang et al. [20] used a hybrid method of design of experiment and grey relational analysis to identify critical criteria and their interactions of multiple criteria decision making problem of different manufacturing processes. Khan et al. [21] investigated the effect of wire electrical discharge machining process parameters on surface roughness of stainless steel specimens using Taguchi based grey relational analysis. Dabade [22] performed multi objective optimization using grey relational analysis to improve the surface integrity of turning process parameters in machining of $\mathrm{Al} / \mathrm{SiCp}$ composites. Jayaraman and Kumar [23] identified the optimum levels of machining parameters of turning AA6063 T6 aluminium alloy based on values of grey relational grade and then determined the significant contribution of parameters by ANOVA. Uddin [24] studied the effect of process parameters and deployed multiobjective optimization approach to determine the optimum set of turning parameters to achieve the best surface finish and circularity of a metallic hip femoral head. Maiyer et al.
[18] illustrated that Taguchi based grey relational analysis is an effective tool for optimization of machining parameters of end milling of Inconel 718 alloy. Patel et al. [25] used grey relation analysis to obtain the single optimal process parameter setting for both responses surface roughness and casting destiny in squeeze casting process. Until now, however, grey based Taguchi approach has not been applied in rotary diamond dressing process for obtaining optimal parameter setting. It can be added that rotary diamond dressing has complex relationships among its process parameters which affect the dressing performance $[5,12]$. The grey system theory is found to be useful when complicated inter-relationships among multiple performance response parameters need to be optimized effectively [26, 27]. Grey based Taguchi approach converts the complicated multiple performance response parameters into optimization of a single grey relational grade. As mentioned earlier, optimization of parameters of rotary diamond dressing has multiple response parameters with conflicting objectives (high dressing ratio and low overlapped dressing area). Furthermore, most researchers did not study the combined influence of process parameters on the performance responses. In this research, grey based Taguchi approach is utilized for multiple response optimizations of rotary diamond dressing and to study the effect of the mentioned process parameters along with their interaction with the dressing response parameters.

\section{EXPERIMENTAL WORK}

For the experimental work, six process parameters (as mentioned earlier) each at either three or two levels have been decided. The process parameters are renamed as factors and the levels of the individual parameters are given in Tab. 1. Usually when an experiment has a mix level of qualitative and quantitative factors (refer Tab. 1), mixed level factorial experimental designs are used [28, 29]. Considering experimental cost required and strenuous measurement method, screening of experiments is done by using mixed level fractional factorial design. Here in the study mixed fractional factorial design of L36 (2(3-1) $\times$ $3(3-1))$ is used $[29,30]$. Using L36 orthogonal array, process parameters are set and respective output response parameters namely dressing ratio and overlapped dressed area are obtained. We used a surface grinding machine for dressing and selected prismatic rotary diamond dresser (SDR50L, Noritake Co. Ltd.) as dressing tool. The design parameters of the selected prismatic rotary diamond dresser are as follows: diameter is $50 \mathrm{~mm}$, number of diamond grits are 120 and the size of each diamond grit is $0.2 \mathrm{~mm}$ (i.e., $m=w=0.2$ ). In case of vitrified diamond grinding wheel, commonly employed depth of cut is $2 \mu \mathrm{m}$ to $10 \mu \mathrm{m}$ during dressing. In this research, depth of cut of 2-6 $\mu \mathrm{m}$ is employed during dressing. Rotary diamond dressing is a type of mechanical cutting process and the transferability of the dressing trajectory determines the topography of the working surface of the grinding wheel [4]. In this study, a vitrified diamond grinding wheel of diameter $150 \mathrm{~mm}$ is dressed under oil-mist lubrication. 3D Laser scanning microscope is used for the visualization and measurement of dressed area and overlapped dressed area of grinding wheel surface (refer to Fig. 3(a)-(b)). In this 
research, we have studied $10 \mathrm{~mm}^{2}$ of surface area in the middle part of grinding wheel for each experimental run for the measurement of dressed area and overlapped dressed area. It can be added that in each consecutive pass (i.e., 2nd pass, 3rd pass and so on) the depth of cut is increased which enables the measurement of the dressed area in each pass, as the surface height of dressed area of a pass and dressed area in the following consecutive pass are different due to increased depth of cut.

Table 1 Factors and their levels considered in this study

\begin{tabular}{|c|c|c|c|c|c|c|}
\hline \multirow{2}{*}{ Factors } & \multirow{2}{*}{$\begin{array}{c}\text { Type of } \\
\text { Parameter }\end{array}$} & \multirow{2}{*}{ Symbol } & \multirow{2}{*}{ DOF } & \multicolumn{3}{|c|}{ Levels } \\
\hline & & & & 1 & 2 & 3 \\
\hline Feed of dresser $(\mathrm{mm} / \mathrm{min})$ & $\mathrm{PP}$ & $\mathrm{A}$ & 1 & 1000 & 2500 & \\
\hline Dressing method & PP & $\mathrm{B}$ & 1 & up & down & \\
\hline Grinding wheel velocity $(\mathrm{m} / \mathrm{sec})$ & PP & $\mathrm{C}$ & 1 & 36.7 & 51.3 & \\
\hline Depth of cut $(\mu \mathrm{m})$ & PP & $\mathrm{D}$ & 2 & 2 & 4 & 6 \\
\hline Velocity ratio & PP & $\mathrm{E}$ & 2 & 0.5 & 0.7 & 0.9 \\
\hline Number of pass & PP & $\mathrm{F}$ & 2 & 1 & 2 & 3 \\
\hline Size of diamond grit $(\mathrm{mm})$ & DP & $\mathrm{G}$ & 0 & \multicolumn{3}{|c|}{0.2} \\
\hline Number of diamond grit & DP & $\mathrm{H}$ & 0 & \multicolumn{3}{|c|}{120} \\
\hline Grinding wheel dia (mm) & DP & I & 0 & \multicolumn{3}{|c|}{140} \\
\hline Rotary diamond dresser dia (mm) & DP & $\mathrm{J}$ & 0 & \multicolumn{3}{|c|}{50} \\
\hline
\end{tabular}

Table 2 Levels of process parameters based on L36 standard orthogonal array

\begin{tabular}{|c|c|c|c|c|c|c|c|c|c|c|c|c|c|}
\hline \multicolumn{1}{|c|}{ Factor (refer above Tab. 1) } & \multicolumn{1}{|c|}{ Factor (refer above Tab. 1) } \\
\hline Exp. No. & A & B & C & D & E & F & Exp. No. & A & B & C & D & E & F \\
\hline 1 & 1 & 1 & 1 & 1 & 1 & 1 & 19 & 2 & 1 & 2 & 1 & 2 & 1 \\
\hline 2 & 1 & 1 & 1 & 2 & 2 & 2 & 20 & 2 & 1 & 2 & 2 & 3 & 2 \\
\hline 3 & 1 & 1 & 1 & 3 & 3 & 3 & 21 & 2 & 1 & 2 & 3 & 1 & 3 \\
\hline 4 & 1 & 1 & 1 & 1 & 1 & 3 & 22 & 2 & 1 & 2 & 1 & 2 & 2 \\
\hline 5 & 1 & 1 & 1 & 2 & 2 & 1 & 23 & 2 & 1 & 2 & 2 & 3 & 3 \\
\hline 6 & 1 & 1 & 1 & 3 & 3 & 2 & 24 & 2 & 1 & 2 & 3 & 1 & 1 \\
\hline 7 & 1 & 1 & 2 & 1 & 1 & 2 & 25 & 2 & 1 & 1 & 1 & 3 & 2 \\
\hline 8 & 1 & 1 & 2 & 2 & 2 & 3 & 26 & 2 & 1 & 1 & 2 & 1 & 3 \\
\hline 9 & 1 & 1 & 2 & 3 & 3 & 1 & 27 & 2 & 1 & 1 & 3 & 2 & 1 \\
\hline 10 & 1 & 2 & 1 & 1 & 1 & 3 & 28 & 2 & 2 & 2 & 1 & 3 & 2 \\
\hline 11 & 1 & 2 & 1 & 2 & 2 & 1 & 29 & 2 & 2 & 2 & 2 & 1 & 3 \\
\hline 12 & 1 & 2 & 1 & 3 & 3 & 2 & 30 & 2 & 2 & 2 & 3 & 2 & 1 \\
\hline 13 & 1 & 2 & 2 & 1 & 2 & 3 & 31 & 2 & 2 & 1 & 1 & 3 & 3 \\
\hline 14 & 1 & 2 & 2 & 2 & 3 & 1 & 32 & 2 & 2 & 1 & 2 & 1 & 1 \\
\hline 15 & 1 & 2 & 2 & 3 & 1 & 2 & 33 & 2 & 2 & 1 & 3 & 2 & 2 \\
\hline 16 & 1 & 2 & 2 & 1 & 2 & 3 & 34 & 2 & 2 & 1 & 1 & 3 & 1 \\
\hline 17 & 1 & 2 & 2 & 2 & 3 & 2 & 35 & 2 & 2 & 1 & 2 & 1 & 2 \\
\hline 18 & 1 & 2 & 2 & 3 & 1 & 2 & 36 & 2 & 2 & 1 & 3 & 2 & 3 \\
\hline
\end{tabular}

The impact of each process parameters at either three or two levels and their interactions are studied. For each trial experiment in the L36 array, the levels of the design and process parameters are indicated in Tab. 2. The design parameters: grinding wheel diameter, rotary diamond dresser diameter, number and size of diamond grits of the rotary diamond dresser are kept constant for the whole set of experiments (refer to Tab. 1).

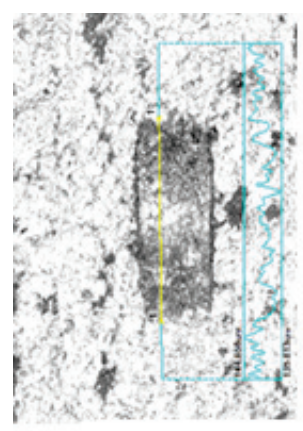

(a)

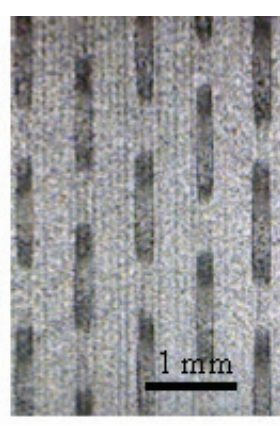

(b)
Figure 3 Dressed vitrified diamond grinding wheel (a) Microscopic view of a dressing trajectory (b) Dressing trajectories
After each run of experiment, the output parameters as the response parameters (dressing ratio and overlapped dressed area) are obtained. In presented multi-criteria approach, there is a need to obtain the signal to noise ratio for both response parameters for each experiment. The attempt is made to calculate and analyze the signal to noise ratio for all experiments, which is presented in the following section.

\section{ANALYSIS OF SIGNAL TO NOISE RATIO}

Signal to noise ratios are commonly used within the context of design of experiments in industry to find the best parameter setting for the process input variables; i.e., the level(s) which will optimize the process output variable [30]. From the literature it is evident that the higher the signal to noise ratio (SNR), the more stable the achievable quality will be [30-32]. Here in this research, the response parameter, 'dressing ratio', needs to be maximized, while the response parameter 'overlapped dressed area' needs to be minimized in order to obtain the overall best dressing performance. Eqs. (1) and (2) are used to calculate SNR for dressing ratio and overlap dressed area respectively. In Eqs. (1) and (2), $y_{i}$ is response parameter value (for $i=1$, 
$2,3, \ldots, n)$ and $n$ is number of replications. For dressing ratio $(\mathrm{R} 1)$ :

$$
(S N R)_{\text {maximize }}=-10 \log _{10}\left(\frac{1}{n} \sum_{i=1}^{n} \frac{1}{y_{i}^{2}}\right)
$$

For overlapped dressed area (R2):

$$
(S N R)_{\text {minimize }}=-10 \log _{10}\left(\frac{1}{n} \sum_{i=1}^{n} y_{i}^{2}\right)
$$

Thus, experiments are performed and response parameters values of dressing ratio (R1) and overlapped dressed area (R2) for each experiment are converted into respective $S N R$ values as per above Eqs. (1) and (2) and are presented in Tab. 3.

Table 3 Signal to noise ratio of dressing ratio and overlapped dressed area obtained from experiments

\begin{tabular}{|c|c|c|c|c|c|}
\hline Exp. No. & SNR for R1 & SNR for R2 & Exp. No. & SNR for R1 & SNR for R2 \\
\hline 1 & 38.49 & -0.14 & 19 & 34.24 & -0.09 \\
\hline 2 & 39.78 & -39.65 & 20 & 38.50 & -34.82 \\
\hline 3 & 39.88 & -39.84 & 21 & 39.89 & -37.81 \\
\hline 4 & 39.93 & -39.87 & 22 & 37.65 & -29.71 \\
\hline 5 & 39.91 & -23.17 & 23 & 39.64 & -37.93 \\
\hline 6 & 39.92 & -39.85 & 24 & 35.58 & -22.08 \\
\hline 7 & 39.87 & -39.83 & 25 & 36.43 & -27.20 \\
\hline 8 & 39.91 & -39.92 & 26 & 38.80 & -33.68 \\
\hline 9 & 39.92 & -36.88 & 27 & 33.10 & -23.81 \\
\hline 10 & 38.74 & -32.11 & 28 & 26.73 & -6.44 \\
\hline 11 & 31.13 & -0.09 & 29 & 36.41 & -31.48 \\
\hline 12 & 32.51 & -14.49 & 30 & 27.04 & -0.09 \\
\hline 13 & 36.94 & -32.17 & 31 & 27.29 & -6.44 \\
\hline 14 & 29.69 & -0.12 & 32 & 27.35 & -0.09 \\
\hline 15 & 36.86 & -35.89 & 33 & 29.97 & -6.44 \\
\hline 16 & 38.54 & -31.71 & 34 & 18.51 & -0.09 \\
\hline 17 & 34.54 & -21.14 & 35 & 31.67 & -15.12 \\
\hline 18 & 36.81 & -36.10 & 36 & 33.58 & -20.09 \\
\hline $\begin{array}{l}\text { Note: SNR for R1 - Signal to noise ratio for dressing ratio and SNR for R2 - Signal to noise ratio for } \\
\text { overlapped area }\end{array}$ & & & & \\
\hline
\end{tabular}

From Tab. 3, it can be found that maximum value of SNR (higher-the-better) is 39.93 for the response parameter 'dressing ratio'. The corresponding experimental 4 and the level of the experimental factors (see Tab. 2) are: $1000 \mathrm{~mm} / \mathrm{min}$ for feed of dresser, up-cut for dressing method, $36.7 \mathrm{~mm} / \mathrm{min}$ for grinding wheel velocity, $2 \mu \mathrm{m}$ for depth of cut, 0.5 for velocity ratio, and number of pass equal to three. On the other hand, as can be seen in Tab. 3, minimum value of SNR (lower-the-better) is found to be -39.92 for the response parameter 'overlapped dressed area'. The corresponding experimental 8 and the level of the experimental factors are: $1000 \mathrm{~mm} / \mathrm{min}$ for feed of dresser, up-cut for dressing method, $51.3 \mathrm{~mm} / \mathrm{min}$ for grinding wheel velocity, $4 \mu \mathrm{m}$ for depth of cut, 0.7 for velocity ratio, and number of pass equal to three. It can further be noted that if the above two response parameters are compared based on experimental factors, some corresponding experimental factor levels are found different.

A comprehensive analysis of SNR values for both responses is performed using MINITAB R16 [28]. For both response parameters i.e. 'dressing ratio' and 'overlapped dressed area', the main effect and the interaction plots for SNR are drawn and presented in Fig. 4 and Fig. 5 respectively.

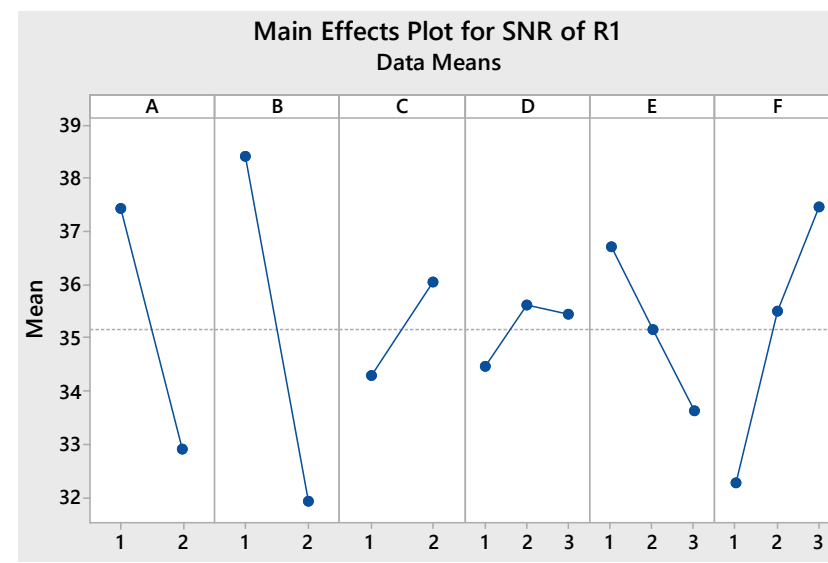

(a)

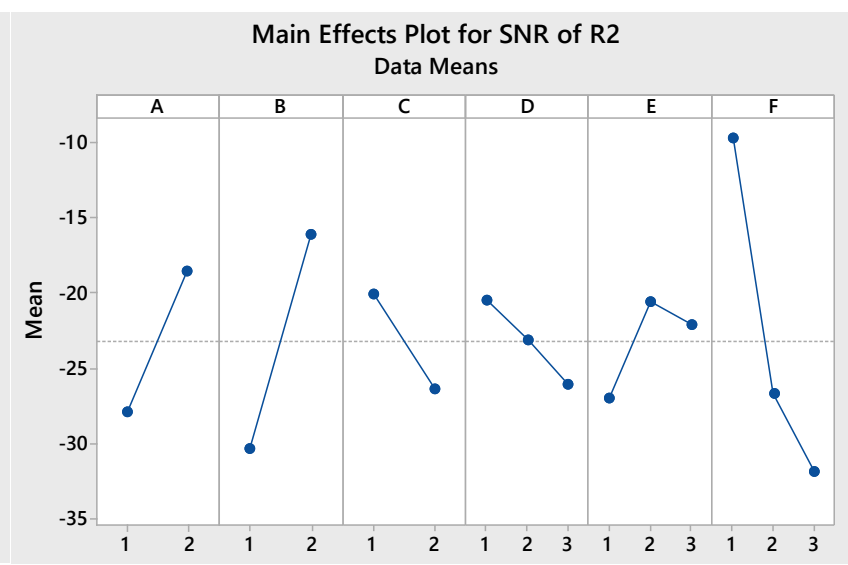

(b)

Figure 4 Main effect plots (a) SNR for dressing ratio (b) SNR for overlapped dressed area

From Fig. 4 one can note the level of each process parameter that helps in achieving the response parameters objective. While, Fig. 5 helps to sort out the pair of any two process parameters which has interaction in favor of targeted response objective. For example, in case of both response parameters (refer Fig. 5(a)-(b)), depth of cut (D) 
has interaction with velocity ratio $(E)$ and number of pass $(F)$. For 'overlapped dressed area', there is an additional interaction between feed of dresser $(A)$ and depth of cut $(D)$ to achieve the target objective. However, dressing method (B) has no interaction with other factors, for both response parameters. Therefore, it is distinct that effect due to the interactions across various parameters is slightly different for dressing ratio and overlapped dressed area, and this must be taken into consideration when choosing the appropriate dressing parameters as well as optimization approach.

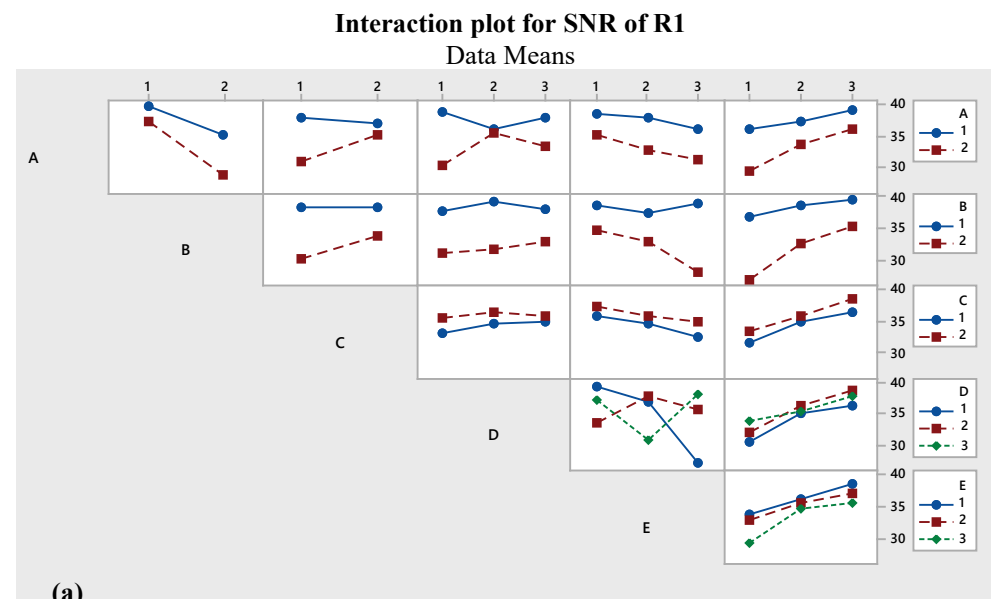

(a)

Interaction plot for SNR of R1

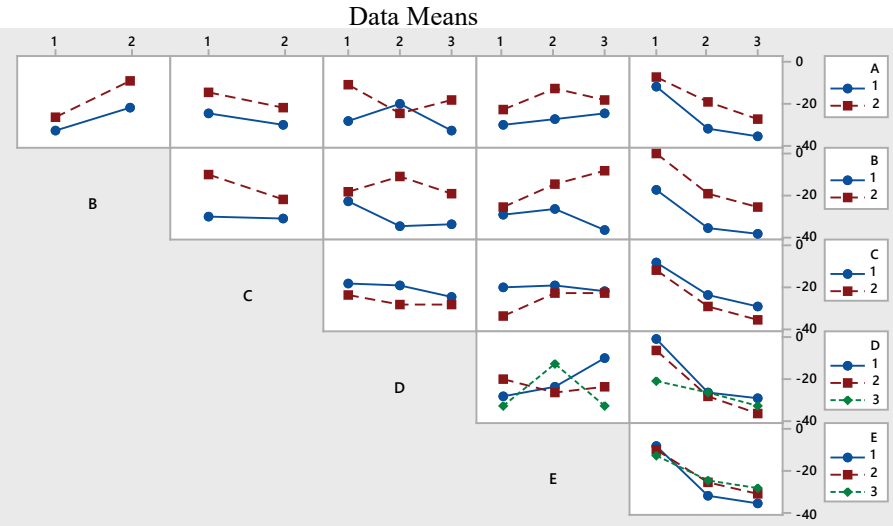

(b)

Figure 5 Interaction plots (a) $S N R$ for dressing ratio (b) SNR for overlapped dressed area

\begin{tabular}{|c|c|c|c|c|c|c|}
\hline \multirow{10}{*}{ For R1 } & Factor & $\mathrm{DF} \#$ & SS & MS & $\mathrm{F}$ & $\mathrm{P}$ \\
\hline & $\mathrm{A}$ & 1 & 165.25 & 165.25 & 36.37 & 0.000 \\
\hline & $\mathrm{B}$ & 1 & 403.62 & 403.62 & 88.83 & 0.000 \\
\hline & $\mathrm{C}$ & 1 & 21.83 & 21.83 & 4.80 & 0.038 \\
\hline & $\mathrm{D}$ & 2 & 19.64 & 9.82 & 2.16 & 0.135 \\
\hline & $\mathrm{E}$ & 2 & 48.25 & 24.13 & 5.31 & 0.012 \\
\hline & $\mathrm{F}$ & 2 & 161.46 & 80.73 & 17.77 & 0.000 \\
\hline & Error & 26 & 118.14 & 4.54 & & \\
\hline & Total & 35 & 937.13 & & & \\
\hline & \multicolumn{6}{|c|}{$\mathrm{R}-\mathrm{Sq}=87.39 \%, \mathrm{R}-\mathrm{Sq}(\mathrm{adj})=75.48 \%$} \\
\hline \multirow{10}{*}{ For R2 } & Factor & DF\# & SS & MS & F & $\mathrm{P}$ \\
\hline & $\mathrm{A}$ & 1 & 641.32 & 641.32 & 11.85 & 0.002 \\
\hline & $\mathrm{B}$ & 1 & 2066.34 & 2066.34 & 38.18 & 0.000 \\
\hline & $\mathrm{C}$ & 1 & 248.42 & 248.42 & 4.59 & 0.042 \\
\hline & $\mathrm{D}$ & 2 & 378.58 & 189.29 & 3.50 & 0.045 \\
\hline & $\mathrm{E}$ & 2 & 102.56 & 51.28 & 0.95 & 0.401 \\
\hline & $\mathrm{F}$ & 2 & 3102.15 & 1551.08 & 28.66 & 0.000 \\
\hline & Error & 26 & 1407.25 & 54.13 & & \\
\hline & Total & 35 & 7941.95 & & & \\
\hline & \multicolumn{6}{|c|}{$\mathrm{R}-\mathrm{Sq}=82.28 \%, \mathrm{R}-\mathrm{Sq}(\mathrm{adj})=76.28 \%$} \\
\hline
\end{tabular}

Analysis of variance (ANOVA) is also used to further assess and determine the relative influence of each experimental factor and the results are presented in Tab. 4. Since $95 \%$ confidence level is used for analysis purpose, 
$p$ value less than 0.05 will establish significance of factor. The factors feed of dresser $(A)$, dressing method (B), grinding wheel velocity $(C)$, velocity ratio $(E)$ and number of pass $(F)$ are significant for the response 'dressing ratio', whereas factor depth of cut $(D)$ is found to be the least significant in the maximization of 'dressing ratio'. R-Sq is found to be about $87.39 \%$, meaning that about 87 percent of variability in dressing ratio is due to the process parameters and their interactions. Similarly, factors feed of dresser $(A)$, dressing method (B), grinding wheel velocity $(C)$, depth of cut $(D)$ and number of pass $(F)$ are significant for the response 'overlapped dressed area', whereas factor velocity ratio $(E)$ is found to be the least significant in the minimization of 'overlapped dressed area'. In this case, R$\mathrm{Sq}$ is determined to be $82.28 \%$, indicating about 82 percent of variability in overlapped dressed area.

As mentioned earlier, optimization of parameters of rotary diamond dressing has multiple response parameters with conflicting objectives. SNR and ANOVA results clearly indicate that a single set of same parameters is not able to provide the desired response parameters. Therefore, it is important to study the influence of process parameters on performance response parameters. In this research, grey based Taguchi approach is utilized for multiple response optimizations of rotary diamond dressing and to study the effect of the mentioned process parameters along with their interaction on the dressing response parameters. The details of optimization approach considered in this study are depicted in the following sections.

\section{MULTI-CRITERIA OPTIMIZATION BASED ON GREY RELATION}

Rotary diamond dressing process is stochastic in nature. Since the process is characterized by random uncertainty, an approach based on integration of signal to noise ratio and grey relational generation is used. The approach was first developed [26] in order to study the uncertainties that exist in the data. It has been applied in the areas such as decision making [33], manufacturing [19, 34], and product development strategies [35-37] etc. The approach consists of the following steps to generate the global comparison among experiments.

Step 1: Normalization of the experimental results (Signal to noise ratio):

Signal to noise ratio values (refer Tab. 3) for dressing ratio and overlapped dressed area are normalized using Eqs. (3) and (4). Eq. (3) is used for dressing ratio where the objective is to maximize its normalized value, while for the overlapped dress area the objective is to minimize its normalized value (refer to Eq. (4)).

$$
\begin{aligned}
& Z_{i j}=\frac{\max \left(Y_{i j}, i=1,2,3, \ldots, n\right)-Y_{i j}}{\max \left(Y_{i j}, i=1,2,3, \ldots, n\right)-\min \left(Y_{i j}, i=1,2,3, \ldots, n\right)} \\
& Z_{i j}=\frac{Y_{i j}-\min \left(Y_{i j}, i=1,2,3, \ldots, n\right)}{\max \left(Y_{i j}, i=1,2,3, \ldots, n\right)-\min \left(Y_{i j}, i=1,2,3, \ldots, n\right)}
\end{aligned}
$$

In Eqs. (3) and (4), $i=1,2,3, \ldots, n$; where $n$ is the number of experiments and $j=1,2,3, \ldots, m$; where $m$ is the number of performance measures, and $Z_{i j}$ is the normalized value, where $0 \leq Z_{i j} \leq 1$.

Step 2: Setting reference sequence:

Reference sequence $Y_{o j}$ is obtained using Eq. (5).

$Y_{o j}=\left\{\begin{array}{l}\min \forall_{j}\left\{Y_{i j}\right\} \text { for smaller the best }=0 \\ \max \forall_{j}\left\{Y_{i j}\right\} \text { for larger the best }=0\end{array}\right.$

Subsequently, each experiment results are compared with $Y_{o j}$ and the grey relational coefficient is calculated.

Step 3: Calculate Grey relation co-efficient:

For each experimental run, grey relational co-efficient $\left(G R C_{i j}\right)$ is calculated for each response parameters using Eq. (6).

$G R C_{i j}=\frac{\min \left(\Delta_{i j}\right)+\xi \max \left(\Delta_{i j}\right)}{\Delta_{i j}+\xi \max \left(\Delta_{i j}\right)}$

$\xi$ is user-selected resolution coefficient which is defined in the range between zero and one. If experiment parameters are equally weighted, then $\xi=0.5$ as explained by Deng [18] and Wen [19]. $\Delta_{i j}$ is calculated using the Eq. (7).

$\Delta_{i j}=\operatorname{Abs}\left(Y_{o j}-Y_{i j}\right)$

Here, $Y_{o j}$ is reference sequence for the response $j$ and $Y_{i j}$ is response parameter value corresponding to experiment $i$ and the response measure $j$.

Step 4: Calculate Grey relational grade:

For both response parameters, a grey relational grade value $\left(G R G_{i}\right)$ for each experiment is calculated by using the Eq. (8).

$G R G_{i}=\frac{1}{m} \sum_{j=1}^{m} G R C_{i j}$

In Eq. (8), $G R G_{i}$ is the grey relational grade value for the experiment $i . G R C_{i j}$ is the grey relational coefficient corresponding to the experiment $i$ for the response parameter $j$. And $m$ is the number of response parameters. This equation is used, if there is equal weightage to all response parameters. In the case of unequal weights for each response parameters, the above Eq. (8) is extended to Eq. (9), where $W_{k}$ denotes the normalized weight for each response parameters.

$G R G_{i}=\sum_{j=1}^{m} W_{k} G R C_{i j}$

Thus, the above approach converts multiple response parameter values into a single grey relational grade, for each experiment. The experiment with maximum grey relational grade value is ideal and optimized solution. Thus, for a given experimental factor setting, its grey relational grade value reveals the closeness of the experimental performance with respect to the performance of the optimized experimental factor setting. This approach can be used to rank the experimental runs. 


\section{MULTI RESPONSE OPTIMIZATION RESULTS}

SNRs of each response parameter (refer Tab. 3) are taken as input for multi response optimization. As described in Section 4, sequentially SNRs are normalized, grey relational coefficients are obtained for each response parameters, and grey relational grades are obtained for each experiment. The entire results of grey relational grade calculations are summarized in Tab. 5 . It can be seen that the process parameter setting of experiment 5 (first ranked) realizes the best possible optimized response parameters. From main effect plot of grey relational grade (refer to Fig. 6), the optimum levels are found to be $1000 \mathrm{~mm} / \mathrm{min}$ for feed of dresser, up cut for dressing method, $36.7 \mathrm{~mm} / \mathrm{min}$ for grinding wheel velocity, $4 \mu \mathrm{m}$ for depth of cut, 0.7 for velocity ratio, number of pass equal to one.

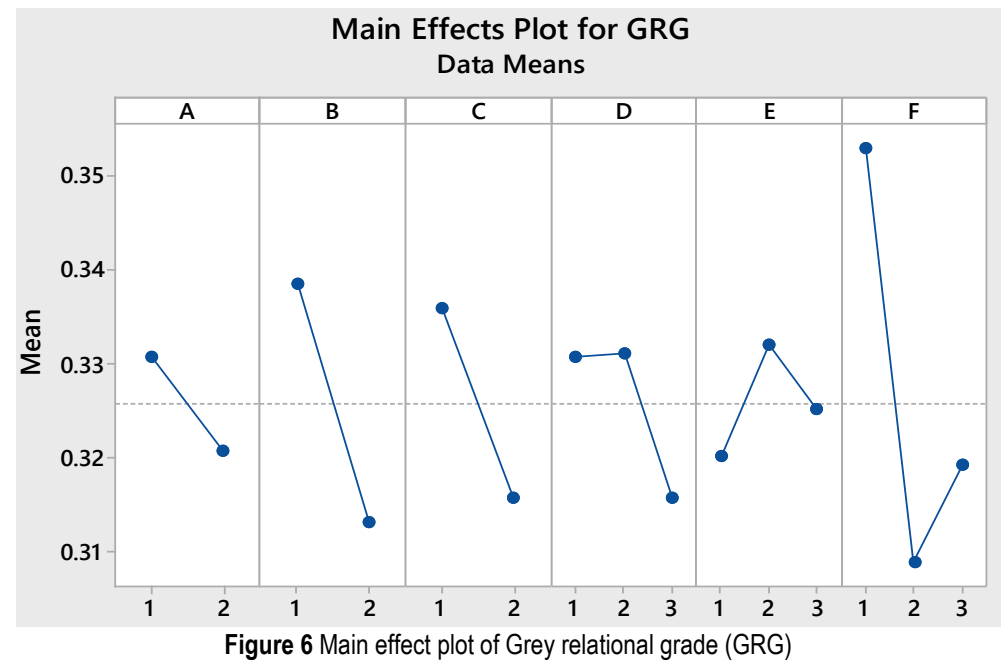

Table 5 Grey relational grade values for each experiment

\begin{tabular}{|c|c|c|c|c|c|c|c|}
\hline Exp. & Run & \multicolumn{2}{|c|}{ Grey relational Generation } & \multicolumn{2}{|c|}{ Grey relation coefficient } & \multicolumn{2}{|c|}{ Grey relation grade } \\
\hline No. & Level & R1 & R2 & $\mathrm{R} 1$ & $\mathrm{R} 2$ & & Rank \\
\hline 1 & 21 & 0.7148 & 1.0000 & 0.3574 & 0.5000 & 0.4287 & 2 \\
\hline 2 & 35 & 0.9252 & 0.3402 & 0.4626 & 0.1701 & 0.3164 & 27 \\
\hline 3 & 32 & 0.9771 & 0.3354 & 0.4885 & 0.1677 & 0.3281 & 16 \\
\hline 4 & 24 & 0.9948 & 0.3347 & 0.4974 & 0.1673 & 0.3324 & 13 \\
\hline 5 & 6 & 0.9974 & 0.7748 & 0.4987 & 0.3874 & 0.4431 & 1 \\
\hline 6 & 9 & 1.0000 & 0.3351 & 0.5000 & 0.1676 & 0.3338 & 9 \\
\hline 7 & 2 & 0.9948 & 0.3356 & 0.4974 & 0.1678 & 0.3326 & 12 \\
\hline 8 & 26 & 0.9974 & 0.3333 & 0.4987 & 0.1667 & 0.3327 & 11 \\
\hline 9 & 31 & 1.0000 & 0.4152 & 0.5000 & 0.2076 & 0.3538 & 4 \\
\hline 10 & 4 & 0.7468 & 0.5515 & 0.3734 & 0.2757 & 0.3246 & 18 \\
\hline 11 & 36 & 0.3784 & 1.0000 & 0.1892 & 0.5000 & 0.3446 & 6 \\
\hline 12 & 1 & 0.4005 & 0.9034 & 0.2003 & 0.4517 & 0.3260 & 17 \\
\hline 13 & 34 & 0.5677 & 0.5496 & 0.2839 & 0.2748 & 0.2793 & 33 \\
\hline 14 & 14 & 0.3589 & 1.0000 & 0.1795 & 0.5000 & 0.3397 & 7 \\
\hline 15 & 29 & 0.5661 & 0.4430 & 0.2830 & 0.2215 & 0.2523 & 35 \\
\hline 16 & 7 & 0.7188 & 0.5627 & 0.3594 & 0.2814 & 0.3204 & 24 \\
\hline 17 & 16 & 0.4536 & 0.8130 & 0.2268 & 0.4065 & 0.3166 & 26 \\
\hline 18 & 28 & 0.5594 & 0.4371 & 0.2797 & 0.2186 & 0.2491 & 36 \\
\hline 19 & 27 & 0.4467 & 1.0000 & 0.2234 & 0.5000 & 0.3617 & 3 \\
\hline 20 & 17 & 0.7188 & 0.4735 & 0.3594 & 0.2367 & 0.2981 & 31 \\
\hline 21 & 22 & 1.0000 & 0.3894 & 0.5000 & 0.1947 & 0.3473 & 5 \\
\hline 22 & 10 & 0.6271 & 0.6182 & 0.3136 & 0.3091 & 0.3113 & 29 \\
\hline 23 & 33 & 0.9342 & 0.3861 & 0.4671 & 0.1930 & 0.3301 & 15 \\
\hline 24 & 13 & 0.4990 & 0.7960 & 0.2495 & 0.3980 & 0.3238 & 21 \\
\hline 25 & 12 & 0.5382 & 0.6839 & 0.2691 & 0.3420 & 0.3055 & 30 \\
\hline 26 & 18 & 0.7693 & 0.5064 & 0.3847 & 0.2532 & 0.3189 & 25 \\
\hline 27 & 15 & 0.4166 & 0.7617 & 0.2083 & 0.3809 & 0.2946 & 32 \\
\hline 28 & 19 & 0.3333 & 0.9593 & 0.1667 & 0.4797 & 0.3232 & 22 \\
\hline 29 & 8 & 0.5405 & 0.5692 & 0.2703 & 0.2846 & 0.2774 & 34 \\
\hline 30 & 3 & 0.3342 & 1.0000 & 0.1671 & 0.5000 & 0.3336 & 10 \\
\hline 31 & 5 & 0.3363 & 0.9593 & 0.1681 & 0.4797 & 0.3239 & 20 \\
\hline 32 & 30 & 0.3360 & 1.0000 & 0.1680 & 0.5000 & 0.3340 & 8 \\
\hline 33 & 11 & 0.3626 & 0.9593 & 0.1813 & 0.4797 & 0.3305 & 14 \\
\hline 34 & 25 & 0.2974 & 1.0000 & 0.1487 & 0.5000 & 0.3244 & 19 \\
\hline 35 & 20 & 0.3872 & 0.8968 & 0.1936 & 0.4484 & 0.3210 & 23 \\
\hline 36 & 23 & 0.4297 & 0.8307 & 0.2148 & 0.4153 & 0.3151 & 28 \\
\hline
\end{tabular}


For $95 \%$ confidence level, the two factors namely, dressing method (B) and number of pass $(F)$, have significant impact on the maximization of dressing ratio and minimization of overlapped dressed area simultaneously (refer to Tab. 6).

The next step is to perform validation experiments for confirming the optimum parameters settings that are obtained for rotary diamond dressing. In the confirmation experiments, the grinding wheel surface topography after rotary diamond dressing is generated using simulation system and compared with the obtained results that are found using the developed method. The details of experiments are illustrated in the following section.

Table 6 ANOVA for grey relational grade values

\begin{tabular}{|c|c|c|c|c|c|}
\hline \multicolumn{5}{|c|}{ Grey relational grade values } \\
\hline Factor & DF & SS & MS & F & P \\
\hline A & 1 & 0.001351 & 0.001351 & 1.55 & 0.225 \\
\hline B & 1 & 0.004781 & 0.004781 & 5.47 & 0.027 \\
\hline C & 1 & 0.002854 & 0.002854 & 3.26 & 0.082 \\
\hline D & 2 & 0.002034 & 0.001017 & 1.16 & 0.328 \\
\hline E & 2 & 0.000282 & 0.000141 & 0.16 & 0.852 \\
\hline F & 2 & 0.010591 & 0.005296 & 6.06 & 0.007 \\
\hline Error & 26 & 0.022732 & 0.000874 & & \\
\hline Total & 35 & 0.046363 & R-Sq = 50.97\%, R-Sq(adj) = 7.10\% \\
\hline \multicolumn{7}{|l|}{} \\
\hline DF: Degree of Freedom, SS: Sum of Squares, MS: Mean Squares (Variance), F: F-value and P: p-value \\
\hline
\end{tabular}

\section{CONFIRMATION EXPERIMENT}

The grey relational grade generation analysis provides the ranking of the parameters setting. As shown in Tab. 5 and Fig. 6, the parameter setting of experiment 5 (first ranked) realizes the best optimized performance response parameters possible. The evaluation of response parameters (i.e. dressing ratio and overlapped dressed area) of the generated grinding wheel surface after rotary diamond dressing is an important issue. Generation of grinding wheel surface topography after dressing by rotary diamond dresser is a complex phenomenon [8, 12, 15]. Subsequently, the grinding wheel surface topography is generated using our developed simulation system [5] for optimum parameters setting of rotary diamond dressing and compared with the experimental results. The process parameters setting of experiment numbers (refer to Tab. 2) $5,1,18$ and 10 are used in simulation model to generate the grinding wheel topography after rotary diamond dressing. The generated topographies are as presented in Fig. 7(a-d). It is mentioned earlier that we studied the $10 \mathrm{~mm}^{2}$ of the surface area in the middle part of grinding wheel for each experimental run for the experimental measurement of dressed area and overlapped dressed area.

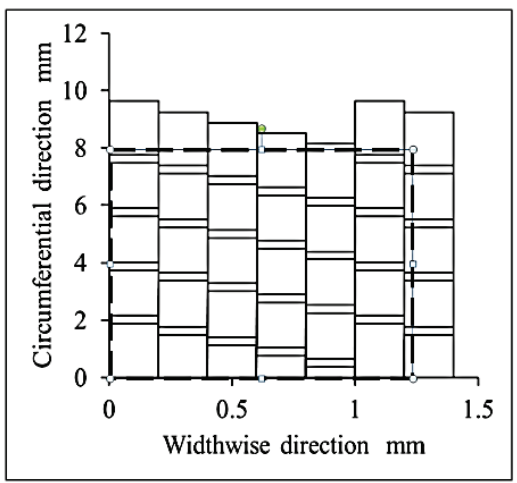

(a) For experiment 5

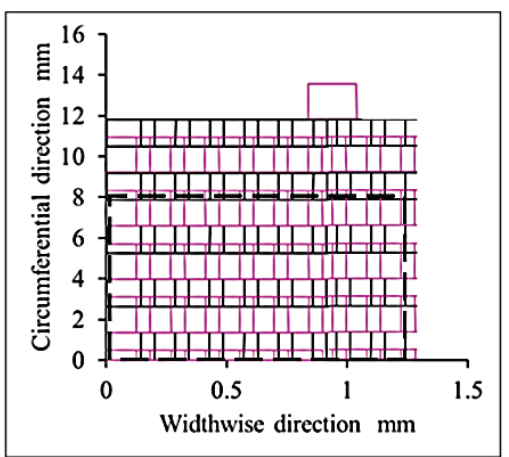

(c) For experiment 18

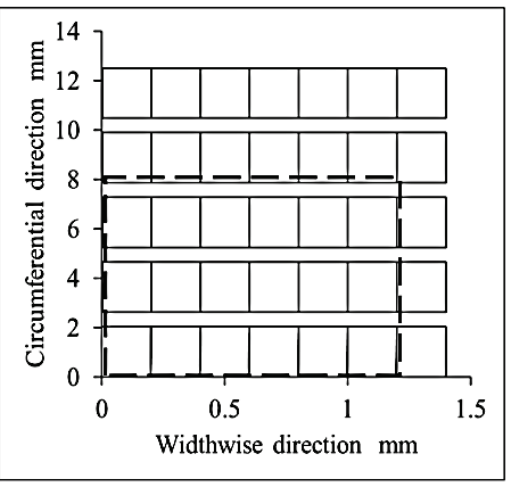

(b) For experiment 1

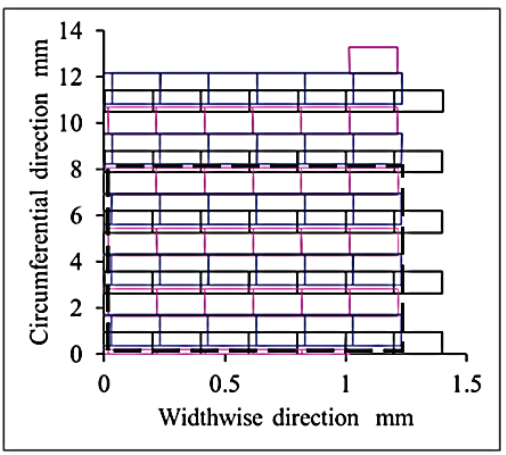

(d) For experiment 10

Figure 7 Generation of the grinding wheel topography after rotary diamond dressing by simulation (black marks are for $1^{\text {st }}$ pass, red marks are for $2^{\text {nd }}$ pass and blue marks are for $3^{\text {rd }}$ pass). Here black dotted box represents $10 \mathrm{~mm}^{2}$ area. 
From simulation result as presented in Fig. 7(a), the generated topography for the first ranked (experiment 5) parameters setting it is found that the dressing ratio is $89 \%$ and the overlapped dressed area is $1.8 \mathrm{~mm}^{2}$ (out of 10 $\mathrm{mm}^{2}$ ). In real measurement of experiment 5 , it is found that dressing ratio is $91 \%$ and $1.5 \mathrm{~mm}^{2}$ of surface area (out of $\left.10 \mathrm{~mm}^{2}\right)$ is overlapped dressed area. From the generated topography of the second ranked (experiment 1) parameters setting (refer Fig. 7(b)) we observe that the dressing ratio is $76 \%$, but there is zero overlapped dressed area. Whereas, in real measurement of experiment 1 , the dressing ratio is found to be $79 \%$ and the overlapped dressed area is $0.7 \mathrm{~mm}^{2}$. Similarly, the parameters setting of experiment 18 (the $36^{\text {th }}$ ranked) is also used to simulate the grinding surface topography after dressing (Fig. 7(c)) and it is found that the dressing ratio is $71 \%$ and the overlapped dressed area is $2.6 \mathrm{~mm}^{2}$. While from the real experiment 18 , the dressing ratio is $67 \%$ and $3.1 \mathrm{~mm}^{2}$ is overlapped dressed area. For the simulation of experiment 10 (18 ${ }^{\text {th }}$ ranked), the generated grinding wheel surface topography (Fig. 7(d)) realizes $94 \%$ dressing ratio and 4.1 $\mathrm{mm}^{2}$ of overlapped dressed area. Whereas, in real measurement of experiment 10 , it is found that dressing ratio is $91 \%$ and $4.5 \mathrm{~mm}^{2}$ is overlapped dressed area. After comparison of simulation and experimental results for the parameter settings of the experiment $5,1,18$ and 10 , it can be stated that the corresponding results from simulation and experiments are in close agreement. The above stated results clearly demonstrate the conformity among the outcome of the multi-criteria optimization, simulation results and real experimental results.

In experiment 18, the number of pass is two and depth of cut is $4 \mu \mathrm{m}$ (which are larger compared to the one used in experiment 5 where number of pass is 1 and depth of cut is $2 \mu \mathrm{m})$, which confirms that higher number of pass and larger depth of cut increases the possibility of overlapped dressed area [8].

\section{CONCLUSION}

In this paper, optimization of rotary diamond dressing has been studied. Experiments are conducted to examine the effect of process parameters on the response parameters i.e., dressing ratio and overlapped dressed area. Grey relational optimization approach is used. Based on the results, the following conclusions can be made:

- Using the signal to noise ratio analysis, dressing ratio and overlapped dressed area are optimized individually. Two different sets of optimal parameter settings are found for dressing ratio and overlapped dressed area. Here, by using analysis of variance, parameters namely feed of dresser, dressing method, grinding wheel velocity, velocity ratio and number of pass are found to be significant factors for the response parameter 'dressing ratio'. For 'overlapped dressed area', feed of dresser, dressing method, grinding wheel velocity, depth of cut and number of pass are significant factors.

- Multi criteria grey relational generation is adopted to determine the optimum parameter setting to optimize both response parameters together. This approach converts multiple response parameter values into single grey relational grade, for each experiment. From analysis of variance of grey relational grade, it is evident that dressing method and number of pass are significant factors while both the response parameters are optimized simultaneously.

- Grey relational generation provides the optimum parameter setting for the rotary diamond dressing and the setting of different process parameters are as follows: $1000 \mathrm{~mm} / \mathrm{min}$ for feed of dresser, up cut for dressing method, $36.7 \mathrm{~mm} / \mathrm{min}$ for grinding wheel velocity, $4 \mu \mathrm{m}$ for depth of cut, 0.7 as velocity ratio and number of pass equal to one.

\section{Acknowledgements}

The author would like to acknowledge the support provided by the Deanship of Scientific Research at King Saud University, through the Research Centre at the College of Engineering.

\section{REFERENCES}

[1] Salmon, S. C. (1992). Flat surface grinding process. Modern grinding process technology, McGraw-Hill: USA, pp. 161183.

[2] Bilek, O., Hrdina, J., Lukovics, I., Pero, R., \& Samek, D. (2014). Improved shape of rotating grinding wheels for high speed grinding. Tehnički vjesnik, 21(1), 63-68.

[3] Rowe, W. B. (2013). Principles of modern grinding technology, William Andrew.

[4] Wegener, K., Hoffmeister, H.-W., Karpuschewskic, B., Kustera, F., Hahmannb, W.-C., \& Rabieya, M. (2011). Conditioning and monitoring of grinding wheels. CIRP Annals-Manufacturing Technology, 60(2), 757-777. https://doi.org/10.1016/j.cirp.2011.05.003

[5] Chowdhury, M. A. K, Kubo, A., Tamaki, J., \& Ullah, A. M. M. (2013). Computer-aided simulation of rotary diamond dressing based on kinematic analysis. Journal of Advanced Mechanical Design, Systems, and Manufacturing, 7(4), 506520. https://doi.org/10.1299/jamdsm.7.506

[6] Mochida, Y., Nishioka, T., Nishioka, T., Kubo, A., \& Jun'ichi, T. (2010). Evaluation of diamond dressers and estimation of grinding performance by dressing force measurement. International Journal of Abrasive Technology, 3, 37-50. https:// doi.org/10.1504/IJAT.2010.032461

[7] Huang, H. (2001). Effects of truing/dressing intensity on truing/dressing efficiency and grinding performance of vitrified diamond wheels. Journal of Materials Processing Technology, 117(1), 9-14. https://doi.org/10.1016/S0924-0136(01)01004-4

[8] Chowdhury, M. A. K. (2015). Grinding wheel surface topography for multiple pass with incremental depth of cut of rotary diamond dresser. Proceedings of the ASME 2015 International Mechanical Engineering Congress \& Exposition / Texas, USA, Nov 13-19, Paper No. IMECE2015-53342, pp. V02BT02A016, 5 pages. https://doi.org/10.1115/IMECE2015-53342

[9] Niiya, H. (1997). Truing and dressing in internal grinding. Mechanical Engineering, 45(12), 43.

[10] Yokogawa, M. \& Furukawa, Y. (1994). Dressing performance of prismatic monocrystaline diamond dresser. JSPE Journal, 60(6), 803-806. (in Japanese)

[11] Yokogawa, M. \& Furukawa, Y. (1989). Dressing accuracy of superabrasive wheels dressed by Kelly driven rotary diamond dresser. JSPE Journal, 55(12), 2254. (in Japanese) https://doi.org/10.2493/jsspe.55.2254

[12] Kubo, A., Chowdhury, M. A. K., Noda, S., Tamaki, J., \& Sharif Ullah, A. M. M. (2013). Visualization of 3D 
topography of grinding wheel surface dressed by rotary diamond dresser. Advanced Materials Research, 797, 751756. https://doi.org/10.4028/www.scientific.net/AMR.797.751

[13] Chowdhury, M. A. K., Tamaki, J., Kubo, A., \& Ullah, A. M. M. S. (2012). Visualization of grinding wheel surface topography for multiple passes of rotary diamond dresser. Advanced Materials Research, 565, 222-227. https://doi.org/10.4028/www.scientific.net/AMR.565.222

[14] Xie, J., Tang, Y., \& Tamaki, J. (2006). A study on surface generation of metal-bonded diamond grinding wheel dressed by electro-contact discharge. Key Engineering Materials, 304-305, 76-80. https://doi.org/10.4028/www.scientific.net/KEM.304-305.76

[15] Klocke, F. \& Linke, B. (2008). Mechanisms in the generation of grinding wheel topography by dressing. Production Engineering, 2(2), 157-163. https://doi.org/10.1007/s11740-008-0101-9

[16] Bzymek, Z. M., Duzy, G. M., \& Mindek, R. B. (2009). Virtual truing and dressing of grinding wheel. Key Engineering Materials, 389-390, 362-367. https://doi.org/10.4028/www.scientific.net/KEM.389-390.362

[17] Tsao, C. (2009. Grey-Taguchi method to optimize the milling parameters of aluminum alloy. The International Journal of Advanced Manufacturing Technology, 40(1-2), 41-48. https://doi.org/10.1007/s00170-007-1314-3

[18] Maiyar, L. M., Ramanujam, R., Venkatesana, R., \& Jerald, J. (2013). Optimization of machining parameters for end milling of Inconel 718 super alloy using Taguchi based grey relational analysis. Procedia Engineering, 64, 1276-1282. https://doi.org/10.1016/j.proeng.2013.09.208

[19] Huang, J.-T. \& Liao, Y.-S. (2003). Optimization of machining parameters of wire-EDM based on grey relational and statistical analyses. International Journal of Production Research, 41(8), 1707-1720. https://doi.org/10.1080/1352816031000074973

[20] Wang, P., Meng, P., Zhai, J., \& Zhu, Z. (2013). A hybrid method using experiment design and grey relational analysis for multiple criteria decision making problems. KnowledgeBased Systems, 53, 100-107. https://doi.org/10.1016/j.knosys.2013.08.025

[21] Khan, Z. A., Siddiquee, A. N., Khan, N. Z., Khan, U. K., \& Quadirc, G. A. (2014). Multi response optimization of wire electrical discharge machining process parameters using Taguchi based grey relational analysis. Procedia Materials Science, 6, 1683-1695. https://doi.org/10.1016/j.mspro.2014.07.154

[22] Dabade, U. A. (2013). Multi-objective process optimization to improve surface integrity on turned surface of $\mathrm{Al} / \mathrm{SiCp}$ metal matrix composites using grey relational analysis. Procedia CIRP, 7, 299-304. https://doi.org/10.1016/j.procir.2013.05.051

[23] Jayaraman, P. \& Kumar, L. (2014). Multi-response Optimization of Machining Parameters of Turning AA6063 T6 Aluminium Alloy using Grey Relational Analysis in Taguchi Method. Procedia Engineering, 97, 197-204. https://doi.org/10.1016/j.proeng.2014.12.242

[24] Uddin, M. (2014). On the influence and optimisation of cutting parameters in finishing of metallic femoral heads of hip implants. The International Journal of Advanced Manufacturing Technology, 73(9-12), 1523-1532. https://doi.org/10.1007/s00170-014-5946-9

[25] Patel, G. M., Krishna, P., \& Parappagoudar, M. B. (2014). Optimization of squeeze cast process parameters using Taguchi and grey relational analysis. Procedia Technology, 14, 157-164. https://doi.org/10.1016/j.protcy.2014.08.021

[26] Deng, J.-L. (1989). Introduction to grey system theory. The Journal of Grey System, 1(1), 1-24.

[27] Lin, C. L., Lin, J. L., \& Ko, T. C. (2002). Optimisation of the EDM process based on the orthogonal array with fuzzy logic and grey relational analysis method. The International
Journal of Advanced Manufacturing Technology, 19(4), 271-277. https://doi.org/10.1007/s001700200034

[28] Sleeper, A. (2012). Minitab Demystified, McGraw Hill.

[29] Montgomery, D. C. (2008). Design and analysis of experiments, John Wiley \& Sons.

[30] Barker, T. B. (1990). Engineering quality by design: interpreting the Taguchi approach. CRC Press.

[31] Devor, R. E., Chang, T., \& Sutherland, J. (1992). Statistical Quality Design and Control: Contemporary Concepts and Methods. MacMillan.

[32] Holmes, D. S. \& Mergen, A. E. (1995). An alternative method to test for randomness of a process. Quality and reliability engineering international, 11(3), 171-174. https://doi.org/10.1002/qre.4680110306

[33] Wen, K.-L. (2004). Grey systems: modeling and prediction. Yang's Scientific Research Institute.

[34] Sood, A., Ohdar, R., \& Mahapatra, S. S. (2010). Parametric appraisal of fused deposition modelling process using the grey Taguchi method. Proceedings of the Institution of Mechanical Engineers - Part B: Journal of Engineering Manufacture, 224(1), 135-145. https://doi.org/10.1243/09544054JEM1565

[35] Tarng, Y. S., Juang, S. C., \& Chang, C. H. (2002). The use of grey-based Taguchi methods to determine submerged arc welding process parameters in hard facing. Journal of Materials Processing Technology, 128(1), 1-6. https://doi.org/10.1016/S0924-0136(01)01261-4

[36] Chan, J. W. \& Tong, T. K. (2007). Multi-criteria material selections and end-of-life product strategy: Grey relational analysis approach. Materials \& Design, 28(5), 1539-1546. https://doi.org/10.1016/j.matdes.2006.02.016

[37] Chan, J. W. (2008). Product end-of-life options selection: grey relational analysis approach. International Journal of Production Research, 46(11), 2889-2912. https://doi.org/10.1080/00207540601043124

\section{Contact information:}

M. A. K. CHOWDHURY, Assistant Professor

Corresponding author

Industrial Engineering Department, King Saud University

P.O. Box 800, Riyadh 11421, Kingdom of Saudi Arabia

Email: mchowdhury@ksu.edu.sa

Ateekh Ur REHMAN, Associate Professor

Industrial Engineering Department, King Saud University

P.O. Box 800, Riyadh 11421, Kingdom of Saudi Arabia

Email: arehman@ksu.edu.sa

\section{S. UDDIN, Lecturer}

School of Engineering, University of South Australia,

Adelaide, Australia

Email: Mohammad.Uddin@unisa.edu.au

Mohammed ALKAHTANI, Assistant Professo

Industrial Engineering Department, King Saud University

P.O. Box 800, Riyadh 11421, Kingdom of Saudi Arabia

Email: moalkahtani@ksu.edu.sa

Saqib ANWAR, Assistant Professor

Industrial Engineering Department, King Saud University

P.O. Box 800, Riyadh 11421, Kingdom of Saudi Arabia

Email: sanwar@ksu.edu.sa 